\title{
ENVIRONMENTAL POLLUTION FROM WASTE AND BIOMASS ENERGY GENERATION
}

\author{
E.C. RADA \\ University of Trento, Civil, Environmental and Mechanical Department, Trento, Italy.
}

\begin{abstract}
In the sectors of waste and biomass to energy, some debatable paradigms persist both among the specialists and among the population, concerning the performances of a few energy options. The present article wants to give a contribution to clarify the debate related to three cases: (a) local impact of waste to energy plants, from conventional solutions to innovative ones (thermochemical processes); (b) local impact of Solid Recovered Fuel generation before energy exploitation; (c) local impact of combustion of wood. Three key articles have been selected from the Author's production (more than one hundred Scopus indexed works) in order to perform a deeper analysis. Results demonstrate that, changing the perspective, some paradigms on the environmental performances of a few waste and biomass options for energy generation must be at least modified.

Keywords: air, biomass, emission, pollution, waste.
\end{abstract}

\section{INTRODUCTION}

The interest on $\mathrm{CO}_{2}$ emissions and greenhouse gas balances [1] often concentrates the attention of the specialists and decision makers mainly on the global impact of energy generation from waste and biomass leaving the local impact on air quality as a secondary, less relevant, topic. That can be seen, for instance, from the production, Scopus certified, of articles on 'greenhouse gas waste management' and 'greenhouse gas biomass management': in the last 5 years, around 200 and 100 articles per year have been indexed referring to these topics, respectively; in this frame, the production of articles on the role on the local air quality of the pollutants respectively emitted accounts for around one order of magnitude less, demonstrating that the attention of the researchers on the local potential effects on the human being is lower.

On the contrary, the present article wants to point out that the choices on the strategies for $\mathrm{CO}_{2}$ emission reductions should be developed in parallel (and not only sequentially) with the analysis of the local effects of the related emissions. It does not make sense to implement a strategy that helps the Planet but impacts significantly on the health of the local population where the related action is developed.

Many scientific articles are oriented to analyze the environmental performances with an approach based only on Life Cycle Assessment (LCA) studies [2-7]. Results are used to make choices but, again, a choice could be globally favourable and locally critical if the site thought for the implementation of the energy plant is not adequate or if the management of the pollutants emitted is not good. This problem cannot be detected if only an LCA is developed.

For the above-mentioned reasons, this article overviews some criticalities and potentialities of waste to energy and biomass to energy options, not always clear to whom are asked to manage strategies or to whom wish to participate to the debate. 


\section{MATERIALS AND METHODS}

The first step of this work was an analysis of the international literature produced by the Author in order to select case studies of waste and biomass conversion to energy where the local impact is seen from unconventional perspectives. Indeed most of the Author's activity indexed in the ISI and Scopus databases has been oriented to find unexpected anomalies in the conventional management of waste and biomass, placing the population at the first place of the attention.

- Results of this analysis have been organized according to the following criteria:

- Local impact of waste to energy plants (thermochemical processes).

- Local impact from plants aimed to Solid Recovered Fuel generation before energy exploitation.

- Local impact of combustion of wood.

Three key articles have been selected from the Author's production of more than one hundred Scopus indexed works.

The first one [8] is useful to discuss the paradigm according to an innovative option of waste to energy should be surely less environmentally impacting at local level when compared with the most conventional solution (combustion with energy recovery).

The second one [9] is useful to discuss the paradigm according to waste and dioxin would have a strict link only when thermochemical processes are adopted, whilst a biochemical process would be exempted.

The third one [10] is useful to discuss the paradigm according to energy generation from wood combustion would be a clean (or near clean) option as this fuel has a natural origin.

\section{RESULTS AND DISCUSSION}

In the sector of municipal solid waste management, the performances of conventional and innovative thermo-chemical processes are still subject of discussion in technical and non-technical environments. An aspect that can make critical the choice of decision makers depends on the stage of the pathway of selection: often they select a technology before analyzing the local environmental impact of the available options; indeed, this type of study is generally developed when the design of the plant has been carried out. The selected article [8] offers quantitative results of a local comparative analysis among technologies operating in the same conditions (location of the plant, stack characteristics). The selected processes concerned combustion, gasification and pyrolysis, alone or in combination. The pollutants considered were both carcinogenic and non-carcinogenic. The reference location of the plant was in an alpine region. Its contribution to the local air pollution was assessed by modeling [8]. For each technology, the local incidence of the plant was assessed and became the input of the comparative analysis of the present article.

In order to compare the impact of the technologies, in the present article a few radar graphs have been generated starting from the available data (all coming from ISI articles). Normalization has been made placing at $100 \%$ the impact of the pollutant of the most impacting technology (pollutant by pollutant).

In Fig. 1, performances of each technology are shown in details. The wider is the area of a radar graph, the higher is the impact of the technology, comparatively.

It is clear that in some cases, an innovative technology can give interesting advantages for some pollutants. However, this result cannot be generalized because the case of pyrolysis 


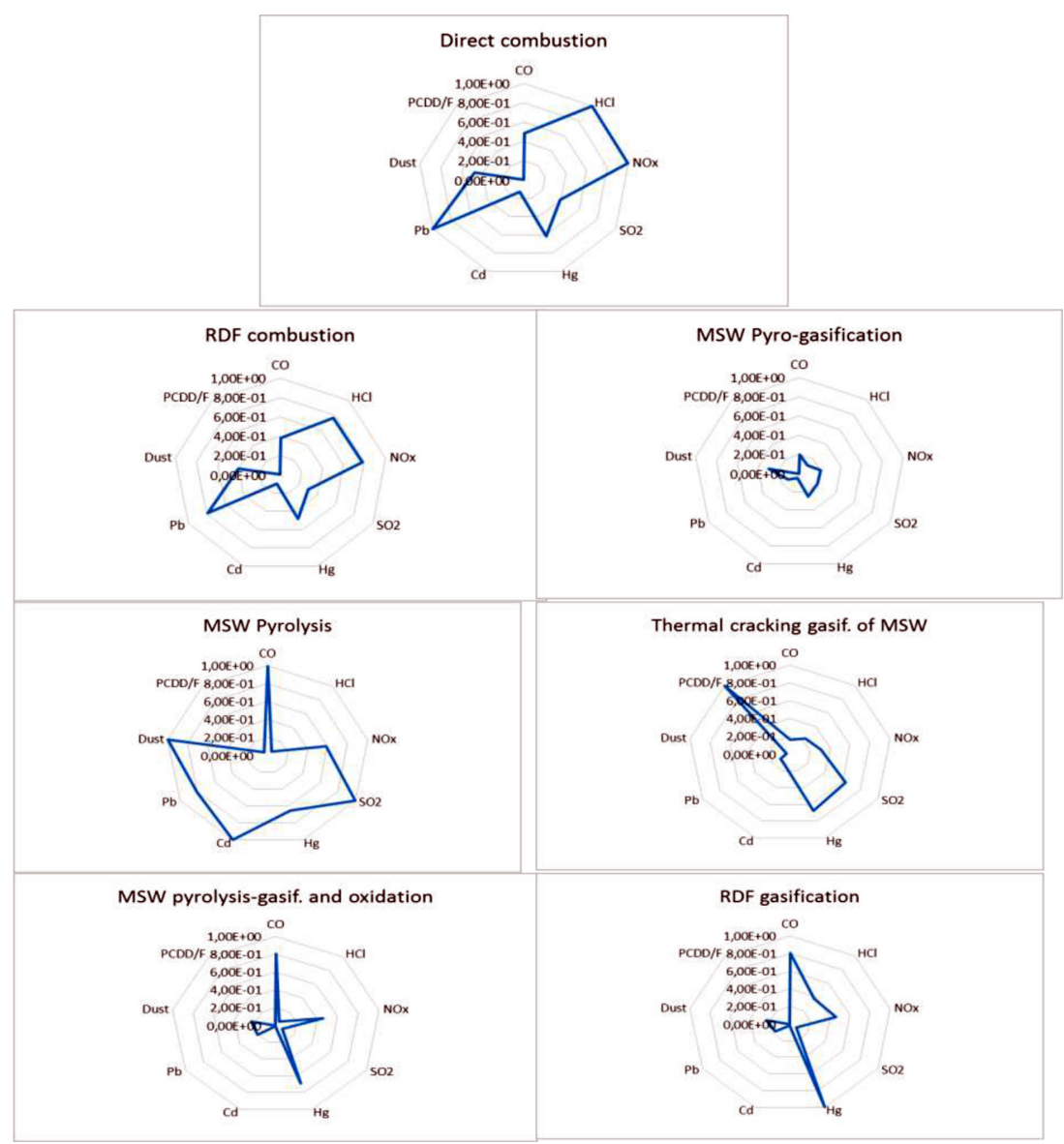

Figure 1: Comparison of the (normalized) impact of thermochemical plants on the local air quality.

is bad for many parameters. The reason depends on the fact that pyrolysis gives three kinds of products: syngas, tar (liquid) and char (solid). When char is combusted (as in the case of the comparison), the performance of the energy conversion can be lower than an optimized combustion in a dedicated incinerator.

From Fig. 1, it is clear that gasification gives advantages as the product is a combustible gas whose energy valorization can be optimized as its oxidation can be easily regulated.

From a wider perspective, the graphs in Fig. 1 demonstrate a moderate variability of the performances of the thermochemical processes.

Summing up, the paradigm related to the absolute advantages of innovative technologies for energy conversion of waste partially fails.

Biomechanical treatment of residual MSW $[11,12]$ can be performed for the generation of an industrial fuel named Solid Recovered Fuel (SRF) for the following usage in cement works or in thermal power plants. It is common opinion that the local impact of this option depends mostly on the final exploitation of the energy content of SRF. This paradigm fails if we look at Fig. 2 obtained by a rearrangement of data available in the literature [9]. The example 


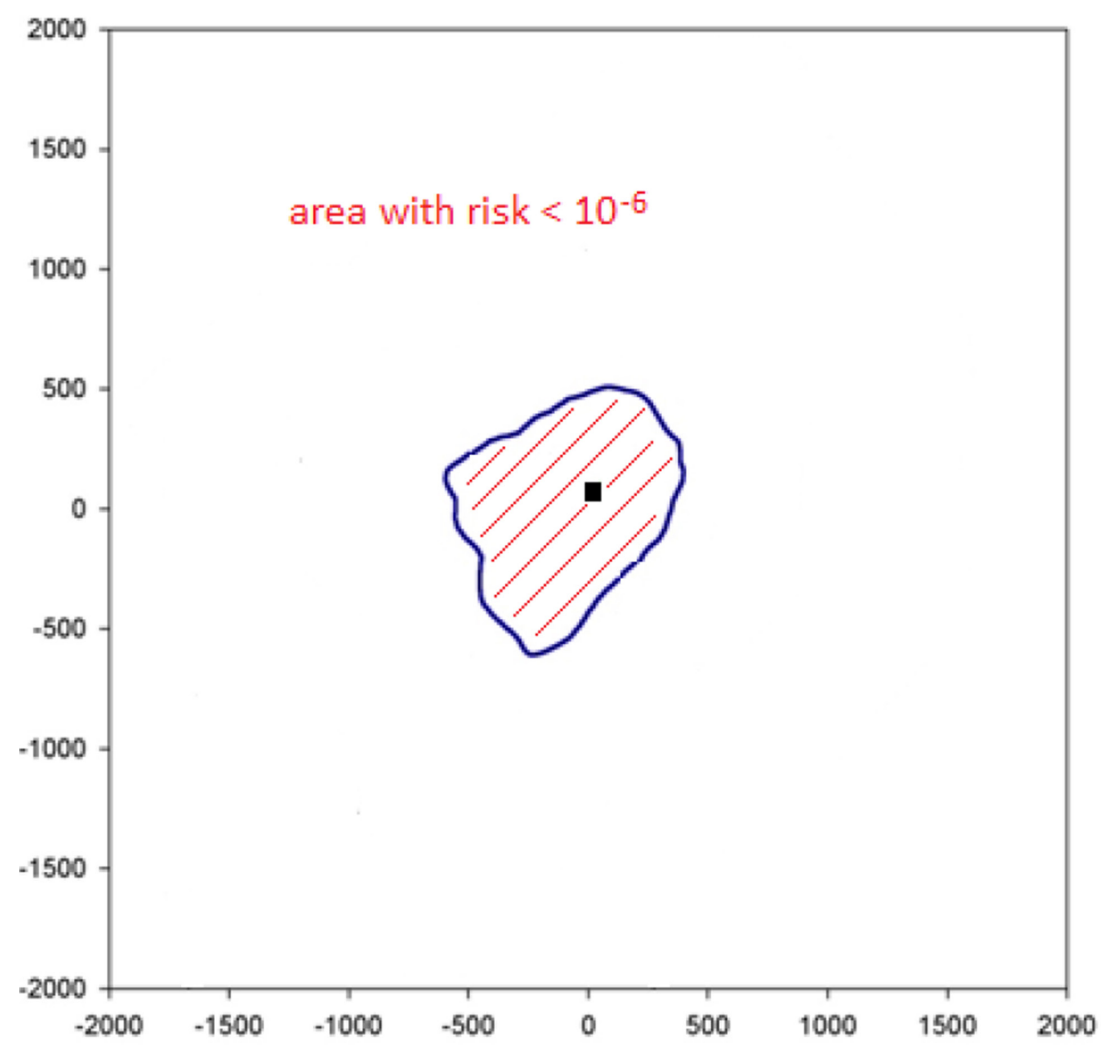

Figure 2: Potential impact of a residual MSW bio-drying plant, serviced by a bio-filter, on the local air quality. Blue-red area: risk $>10^{-6}$. Black square: plant. Axes in meters.

refers to bio-drying coupled with a bio-filter aimed to exhausted air treatment. The advantage of bio-filter is the low cost, but the limit is the way of releasing the residual pollutants into the atmosphere: low temperature, low speed and low height are unfavorable for a good dilution and a reduced deposition. In the last decade, an unexpected phenomenon has been pointed out and discussed [9]: the release of PCDD/F from the bio-filter as a consequence of a release (not a generation) of PCDD/F from the consumption of volatile solids during the biological process. In spite of a low emission factor, the bad dilution into the atmosphere can cause an accumulation in the surroundings of a plant with the consequence of overcoming the typical risk limit requested for authorizing an incinerator: $10^{-6}$.

Taking into account the target risk $\left(10^{-6}\right)$, the rearrangement of data on the selected casestudy points out that a significant area of the territory (with a diameter of about $1 \mathrm{~km}$ ) can be affected by inadequate depositions. Technical solutions are available (bio-trickling filters, regenerative thermal oxidizers, etc.) but the absence of this analysis in the pathways for authorizations make this impact underestimated.

Wood is the most used renewable energy source in the Italian Alpine regions but is one of the major sources of particulate matter too. In order to contribute to the assessment of the role of wood combustion to atmospheric pollution, some measurements of the concentration of a specific wood combustion tracer, Levoglucosan (LG), were performed in the selected article [10]. The experimental study was conducted in two urban sites, located in the same alpine 
town, during summer and winter, and in three mountain sites, where wood was expected to be widely used for domestic heating, during winter. Results showed differences between rural and urban areas and between winter and summer. These analyses are suitable when the role of wood combustion must be studied and strategies for air quality improvement must be planned.

Two linear correlations were obtained for the analyzed areas [10], linking the concentrations of $\mathrm{LG}(\mathrm{y})$ and $\mathrm{PM}_{10}(\mathrm{x})$, in $\mu \mathrm{g} / \mathrm{m}^{3}$ :

- Urban area : $\mathrm{y}=0.0051 \mathrm{x}-0.0317 \mathrm{R}^{2}=0.99$

- Mountain : $\mathrm{y}=0.0406 \mathrm{x}-0.2765 \mathrm{R}^{2}=0.86$

When LG (y) is zero, the concentration of $\mathrm{PM}_{10}$ is higher than zero, as expected (wood combustion is not the unique source of particulate matter). From another point of view, comparing $\mathrm{x}$ when $\mathrm{y}$ is forced to zero and when $\mathrm{y}$ is assumed as the measured LG concentration, it is possible to verify that the role of wood combustion can be dominant in Alpine areas,



Figure 3: Example of a comparison of the impact of a centralized wood combustion for district heating (plant) on the local quality of particulate matter before and after the substitution of wood domestic boilers (buildings with emissions). 
contributing even more than a half of the particulate matter present in the atmosphere. Thus, a question can rise about which strategy should be implemented to significantly decrease the role of wood combustion in specific areas. A priority should be the modernization of the domestic apparatuses (stoves, boilers, etc.). An alternative could be the centralization of wood combustion to perform district heating. From the point of view of the local environmental impact, an improvement is expected thanks to:

The introduction of a treatment of the off-gases (generally not present at domestic level).

The construction of an adequate stack (optimized according to the parameters height, stack temperature, off-gas velocity at the stack).

However, a worrying can be related to the potential presence of an area of maximum impact where the air quality could not be guaranteed. I order to have a look at the problem, Fig. 3 reports a case-study comparison between the local impact of existing domestic combustors of wood and a proposed centralized wood combustor for district heating in an Alpine valley [13]. The advantages are clear, but it is also clear that, in case of excessive power of the plant, its incidence in the area of highest impact could be critical. Figure 3, obtained rearranging data available in the literature [13] demonstrates that district heating cannot wherever improve the air quality of an area: the balance is negative in the yellow area.

\section{CONCLUSIONS AND OUTLOOKS}

This article focused on specific aspect of local environmental impacts from waste and biomass valorization. Results of the performed analysis showed that the local environmental impact of waste to energy plants (adopting thermochemical processes) cannot be minimized only by the choice of an innovative process. Concerning SRF, its generation can have an impact not negligible because of the characteristics of the most common system of exhaust air treatment: bio-filter. Finally, the local impact of domestic combustion of wood can be critical. Advantages from the implementation of a district heating plant could be significant, but a detailed analysis of the local impact of this strategy must be checked, mostly in mountain areas.

\section{REFERENCES}

[1] Cioca, L.I., Ivascu, L., Rada, E.C., Torretta, V. \& Ionescu, G., Sustainable development and technological impact on $\mathrm{CO}_{2}$ reducing conditions in Romania. Sustainability, 7(2), pp. 1637-1650, 2015. http://dx.doi.org/10.3390/su7021637

[2] Rada, E.C., Ragazzi, M., Ionescu, G., Merler, G., Moedinger, F., Raboni, M. \& Torretta, V., Municipal solid waste treatment by integrated solutions: energy and environmental balances. Energy Procedia, 50, pp. 1037-1044, 2014. http://dx.doi.org/10.1016/j.egypro.2014.06.123

[3] Torretta, V., Ionescu, G., Raboni, M. \& Merler, G., The mass and energy balance of an integrated solution for municipal solid waste treatment. WIT Transactions on Ecology and the Environment, 180, pp. 151-161, 2014. http://dx.doi.org/10.2495/WM140131

[4] Ionescu, G., Rada, E.C., Ragazzi, M., Mărculescu, C., Badea, A. \& Apostol, T., Integrated municipal solid waste scenario model using advanced pretreatment and waste to energy processes. Energy Conversion and Management, 76, pp. 1083-1092, 2013.

http://dx.doi.org/10.1016/j.enconman.2013.08.049 
[5] Patrascu, R., Minciuc, E., Tutica, D., Norisor, M., Ionescu, G. \& Stefani, P., Reducing environmental impact through efficient utilisation of biomass in a cogeneration plant. case study - energy supply of an industrial company through biomass utilisation in a cogeneration plant with internal combustion engine. Quality - Access to Success, 15(138), pp. 84-88, 2014.

[6] Ionescu, G., Rada, E.C. \& Cioca, L.I., Municipal solid waste sorting and treatment schemes for maximizing material and energy recovery in a latest EU member. Environmental Engineering and Management Journal, 14(11), pp. 2501-2746, 2015.

[7] Kathiravale, S., Yunus, M.N.M., Sopian, K., Samsuddin, A.H. \& Rahman, R.A., Modeling the heating value of municipal solid waste. Fuel, 82(9), pp. 1119-1125, 2003. http://dx.doi.org/10.1016/S0016-2361(03)00009-7

[8] Ragazzi, M. \& Rada, E.C., Multi-step approach for comparing the local air pollution contributions of conventional and innovative MSW thermo-chemical treatments. Chemosphere, 89(6), pp. 694-701, 2012. http://dx.doi.org/10.1016/j.chemosphere.2012.06.024

[9] Rada, E.C., Ragazzi, M., Zardi, D. \& Laiti, L., PCDD/F environmental impact from municipal solid waste bio-drying plant. Chemosphere, 84(3), pp. 289-295, 2011. http://dx.doi.org/10.1016/j.chemosphere.2011.04.019

[10] Rada, E.C., Ragazzi, M. \& Malloci, E., Role of levoglucosan as a tracer of wood combustion in an alpine region. Environmental Technology, 33(9), pp. 989-994, 2012. http://dx.doi.org/10.1080/09593330.2011.604858

[11] Rada, E.C., Ragazzi, M. \& Badea, A., MSW bio-drying: design criteria from 10 years research. UPB Scientific Bulletin, Serie D, 74(3), pp. 209-216, 2012.

[12] Velis, C.A., Wagland, S., Longhurst, P., Robson, B., Sinfield, K., Wise, S. \& Pollard, S., Solid recovered fuel: materials flow analysis and fuel property development during the mechanical processing of biodried waste. Environmental Science and Technology, 47(6), pp. 2957-2965, 2013. http://dx.doi.org/10.1021/es3021815

[13] http://epidemiologia.ulss20.verona.it/data/55/Eventi/2016/050516/Ragazzi_ 050516. pdf (accessed May 2016). 